\title{
Design and Analysis of a 2-DOFs Right-angle-shape Piezoelectric Energy Harvester
}

\author{
Zhangfang Hu; Ruilin Xu; Yuan Luo; Ruyi Gan \\ Chongqing Municipal Level Key Laboratory of Photoelectronic Information Sensing and Transmitting Technology \\ Chongqing University of Posts and Telecommunications Chongqing, CHINA \\ 2246436584@qq.com
}

\begin{abstract}
In this paper, a 2-DOFs (two-degree-of-freedoms) right-angle-shape piezoelectric energy harvester is designed and analyzed for widening the operation bandwidth (-3dB bandwidth) of piezoelectric energy harvester in low frequency vibration environment. The finite element simulation results show that, the operation bandwidth of the optimized device comprises two operating frequency bands near the first resonant frequency $21.67 \mathrm{~Hz}$ and second resonant frequency $48.75 \mathrm{~Hz}$, the operation bandwidth of two beams are $13.8 \mathrm{~Hz}$ and $14.2 \mathrm{~Hz}$, the outputpowers reach $25 \mathrm{~mW}$ and $41 \mathrm{~mW}$ respectively. It is demonstrated that the 2-DOFs right-angle-shape piezoelectric energy harvester which reduces each order natural frequency, increases the output-power density, and ensures the wide operation bandwidth, could be efficient and adaptive in low-frequency vibration environment.
\end{abstract}

Keywords-piezoelectric energy harvester; low frequency; wide operation bandwidth

\section{INTRODUCTION}

With the rapid development of microelectronics, computer and wireless communication technology, the wireless sensor network technology which consists of a large number of small-size, low-power consumption and low-cost wireless sensor nodes gradually become mature. ${ }^{[1]}$ The wireless sensor network nodes are widely used in civil, industrial and military fields. $^{[2]}$ Conventional chemical batteries cannot meet the energy needs of these low-power devices because of their limited life, difficulties in regular replacing and the environmental pollution. ${ }^{[3]}$ Piezoelectric vibration energy harvesting which can convert the mechanical vibration energy into useful electrical energy has been favored by researchers ${ }^{[4]}$.

Conventional single-degree-of-freedom piezoelectric vibration energy harvester usually consists of a cantilevered beam with a proof mass at its free end. For such a device has a high resonance frequency and narrow operation bandwidth. Aiming at widening the operation bandwidth, $\mathrm{Xue}^{[5]}$ designed a system comprising an array of cantilevered energy harvesters with various aspect ratios. The operation bandwidth of the device can be widened to $16 \mathrm{~Hz}$; $\operatorname{Singh}^{[6]}$ presented a design of nonlinear bi-stable vibration energy harvester, which uses the magnet mass instead of the traditional mass to widen its operation bandwidth. The array type cantilever energy harvesters and the nonlinear bi-stable vibration energy harvester while widen the operation bandwidth, the problems of low output-power density, and high natural frequency are still existed.
Some researchers also widen the operation bandwidth by increasing the degree-of-freedoms and improving the configuration of piezoelectric energy harvesters. $\mathrm{Wu}^{[7]}$ designed and fabricated a 2-DOFs piezoelectric energy harvester which comprises one main cantilever and an inner secondary cantilever, it can achieve two voltage peaks at the two close resonant frequencies in the environment frequency less than $24 \mathrm{~Hz} ; \mathrm{Hu}^{[8]}$ presented a design of a 3-DOFs Mshaped piezoelectric energy harvester comprises a main beam and two folded auxiliary beams interconnected through the proof mass at the end of the main cantilever, it can tune the resonant frequencies of first three orders in the environment frequency less than $30 \mathrm{~Hz}$ close enough to obtain a utility wide bandwidth; Wang ${ }^{[9]}$ designed and fabricated a cantilever type harvester attached with multiply mass at the end of the cantilever, the resonant frequency is reduced with the increase of the numbers of mass, and bandwidth is broadened with numbers of mass. It can be summarized that increasing the degree-of-freedoms of the harvester can effectively reduce the resonant frequency interval results in multiple operating frequency bands at low-frequency environment, but for one single operation bandwidth widening is not satisfactory; increasing the numbers of mass can effectively broaden the single operation bandwidth, but it does not shorten the resonant frequency interval or increase the number of operating frequency bands in the low-frequency environment.

In this paper, a 2-DOFs right-angle-shape piezoelectric energy harvester is designed, it comprises one main cantilever and a secondary cantilever which vertical placed on the mass of the main cantilever. For the purpose of realizing the wide bandwidth in low frequency environment, length ratio of two beams and mass ratio are carefully investigated and optimized. The theoretical and simulate study shows that the 2-DOFs right-angle-shape piezoelectric energy harvester can reduce each order natural frequency, increase output-power density and ensure wide operation bandwidth.

\section{DESIGN AND THEORETICAL ANALYSIS}

Fig.1(a) gives the structure schematic diagram of the 2DOFs right-angle-shape piezoelectric energy harvester. According to the theory of linear multi-degree-of-freedoms, the device can be equivalent transformed into the mass-spring equivalent mode which is shown in Fig.1(b). The equivalent elastic coefficients of main cantilever and secondary cantilever are $k_{1}, k_{2}$ respectively. And the equivalent masses of main cantilever and secondary cantilever are $m_{s 1}, m_{s 2}$ respectively. 


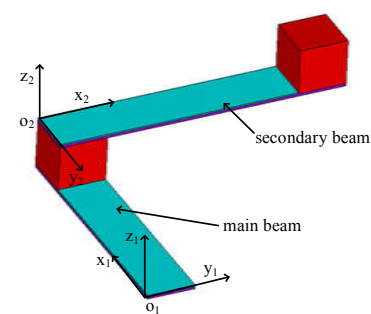

(a)

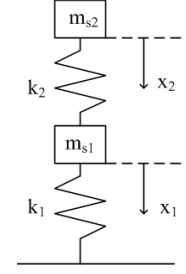

(b)
Fig.1. Schematic of 2-DOFs right-angle-shape piezoelectric energy harvester: (a) the structure of the device; (b) the equivalent model of the device.

The 2-DOFs system starts free vibration in the case of no external force or damping, and the free vibration equation of the system ${ }^{[10]}$ is:

$$
M \ddot{X}+K X=0
$$

The equivalent mass matrix of the system is $M$, and the equivalent stiffness matrix of the system is $K$, and $X$ is the displacement vector of the mass blocks off the equilibrium positions. According to the theory of differential equations and modal analysis, the solution of the equation is:

$$
X=A \sin (\omega \mathrm{t}+\varphi)
$$

Among them, the sufficient and necessary condition for the non-null solution of $A$ is that the intrinsic equation is 0 :

$$
|K-\omega M|=0
$$

The following equation can be obtained for the twodegree-of-freedoms system proposed in this paper:

$$
\left|\begin{array}{cc}
k_{1}+k_{2}-\omega^{2} m_{s 1} & -k_{2} \\
-k_{2} & k_{2}-\omega^{2} m_{s 2}
\end{array}\right|=0
$$

The solution of equation (4) gives the value of the first two order natural frequencies of the 2-DOFs system. Assuming $m_{s 1}=m_{s 2}=m_{0}, k_{1}=k_{2}=k_{0}$, the first two order natural frequencies are: $\omega_{n 1}^{2} \approx 0.382 k_{0} / m_{0} \quad, \quad \omega_{n 2}^{2} \approx 2.618 k_{0} / m_{0}$. Compared with the first order natural frequency ${ }^{[11]}$ of the conventional single-degree-of-freedom piezoelectric cantilever beam structure $\omega_{0}^{2}=k_{0} / m_{0}$, the first order natural frequency of the 2-DOFs system reduces obviously. By changing the equivalent stiffness $k_{1}, k_{2}$ and the equivalent masses $m_{s 1}, m_{s 2}$, each order natural frequency of the 2-DOFs vibration system can be adjusted.

\section{SIMULATION AND DISCUSSION}

In this section, the size parameters of 2-DOFs right-angleshape piezoelectric energy harvester would be discussed by the finite element analysis simulation. Table I shows material parameters of the device specifically.

TABLE I. Material Parameters of the Device

\begin{tabular}{|c|c|c|c|c|c|}
\hline & $\begin{array}{c}\text { Main } \\
\text { beam }\end{array}$ & $\begin{array}{c}\text { Secondary } \\
\text { beam }\end{array}$ & $\begin{array}{c}\text { Piezoelectric } \\
\text { patch }\end{array}$ & $\begin{array}{c}\text { Mass } \\
1\end{array}$ & $\begin{array}{c}\text { Mass } \\
2\end{array}$ \\
\hline $\begin{array}{c}\text { Density } \\
\left(\mathrm{kg} / \mathrm{m}^{3}\right)\end{array}$ & 2700 & 2700 & 7500 & 8900 & 8900 \\
\hline $\begin{array}{c}\text { Modulus of } \\
\text { elasticity } \\
(\mathrm{GPa})\end{array}$ & 69 & 69 & 62 & 206 & 206 \\
\hline $\begin{array}{c}\text { Poisson's } \\
\text { ratio }\end{array}$ & 0.35 & 0.35 & 0.31 & 0.3 & 0.3 \\
\hline
\end{tabular}

A. Effect of two beams length ratio on the output performances of 2-DOFs right-angle-shape piezoelectric energy harvester

Keep the cross section parameters of 2-DOFs right-angleshape piezoelectric energy harvester, namely: the beam width $10 \mathrm{~mm}$, base layer thickness $0.5 \mathrm{~mm}$ and piezoelectric layer thickness $0.3 \mathrm{~mm}$ the same. The mass of two masses $0.89 \mathrm{~g}$ and main beam length $50 \mathrm{~mm}$ remain unchanged, change secondary beam length from $30 \mathrm{~mm}$ to $80 \mathrm{~mm}$.

Fig.2 shows the output voltage of 2-DOFs right-angleshape piezoelectric energy harvester with two beams length ratio $L_{2} / L_{1} 4 / 5,1,6 / 5$ and $7 / 5$ when applied acceleration $1 \mathrm{~g}$. It can be demonstrated that the operation bandwidth of main beam increases first and then decreases, and it reaches the maximum $13.8 \mathrm{~Hz}$ which is the sum of the first bandwidth $8 \mathrm{~Hz}$ $(17.7 \mathrm{~Hz} \sim 25.7 \mathrm{~Hz})$ near the first-order resonant frequency and the second bandwidth $5.8 \mathrm{~Hz}(45.85 \mathrm{~Hz} \sim 51.65 \mathrm{~Hz})$ near the second-order resonant frequency at $L_{2} / L_{1}=6 / 5$. As for the secondary beam, the operation bandwidth of secondary beam increases first and then decreases, and it reaches the maximum $14.3 \mathrm{~Hz}$ which is the sum of the first bandwidth $9.4 \mathrm{~Hz}(16.9 \mathrm{~Hz}$ $\sim 26.5 \mathrm{~Hz})$ near the first-order resonant frequency and the second bandwidth $4.8 \mathrm{~Hz}(46.35 \mathrm{~Hz} \sim 51.15 \mathrm{~Hz})$ near the second-order resonant frequency at $L_{2} / L_{1}=6 / 5$. Therefore, select $6 / 5$ as two beams length ratio $L_{2} / L_{1}$ when optimized.

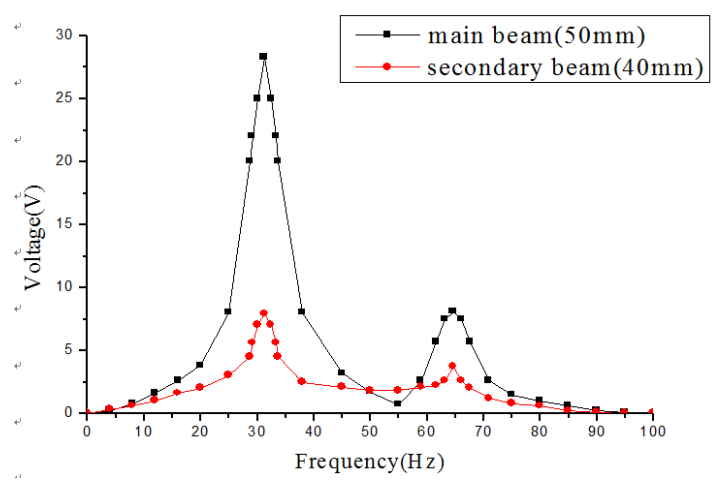

(a) $L_{2} / L_{1}=4 / 5$

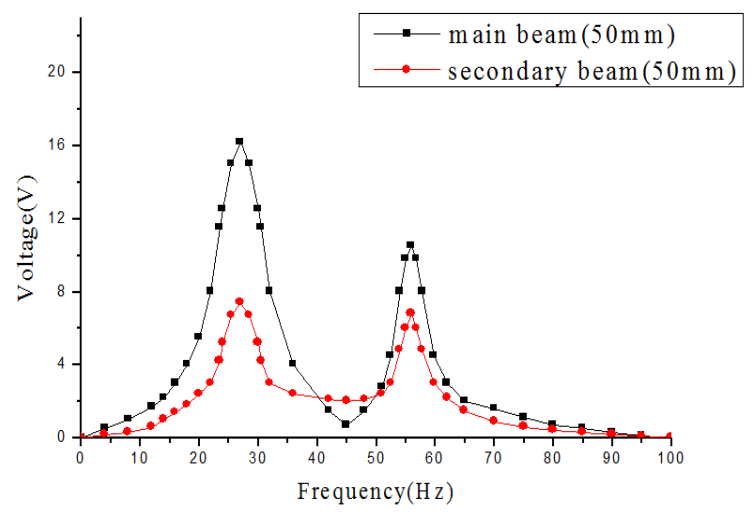

(b) $L_{2} / L_{1}=1$ 


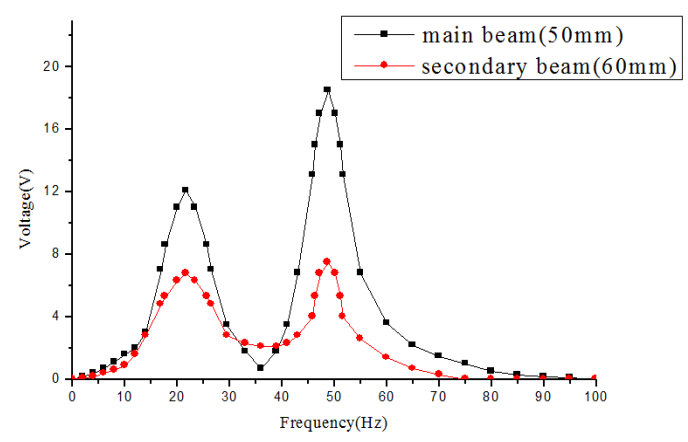

(c) $L_{2} / L_{1}=6 / 5$

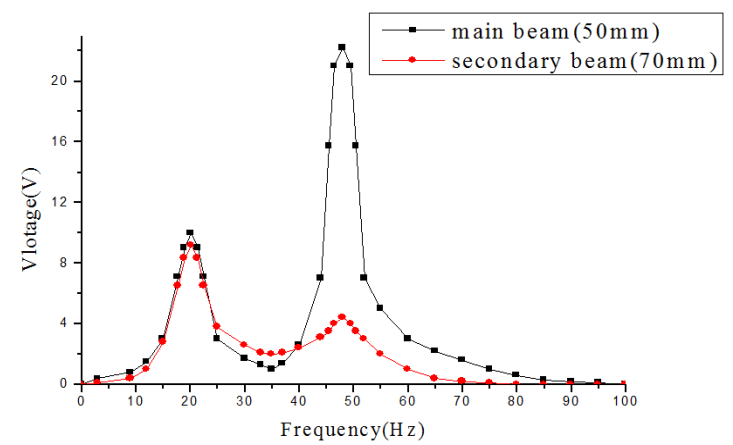

(d) $L_{2} / L_{1}=7 / 5$

Fig.2. The output voltage of 2-DOFs right-angle-shape piezoelectric energy harvester with two beams length ratio $L_{2} / L_{1} 4 / 5,1,6 / 5$ and $7 / 5$.

\section{B. Effect of two masses ratio on the output performances of 2-} DOFs right-angle-shape piezoelectric energy harvester

Keep the cross section parameters of 2-DOFs right-angleshape piezoelectric energy harvester, namely: the beam width $10 \mathrm{~mm}$, base layer thickness $0.5 \mathrm{~mm}$ and piezoelectric layer thickness $0.3 \mathrm{~mm}$ the same. The two beams length ratio $6 / 5$, main beam length $50 \mathrm{~mm}$ and the secondary mass $8.9 \mathrm{~g}$ remain unchanged, change the first mass $30 \mathrm{~mm}$ to $80 \mathrm{~mm}$.

As Fig.3(a) shows that with the two masses ratioincreases, the first two natural frequencies and their interval reduces gradually. In Fig.3(b), it can be demonstrated that the operation bandwidth of two beams increases first and then decreases. The operation bandwidth of main beam reaches the maximum $15.4 \mathrm{~Hz}$ at $M_{1} / M_{2}=0.6$, and the operation bandwidth of secondary beam reaches the maximum $14.2 \mathrm{~Hz}$ at $M_{1} / M_{2}=1$. Therefore, in order to reduce the device frequencies, select two masses ratio $M_{1} / M_{2}=1$ when optimized.

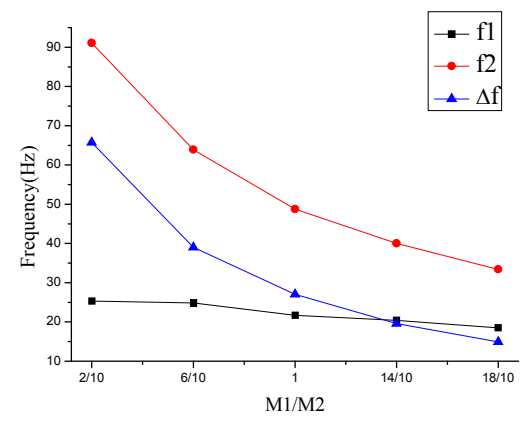

(a)

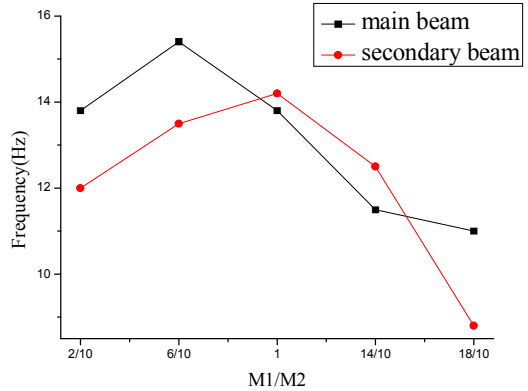

(b)

Fig.3. Effect of two masses ratio $M_{1} / M_{2}$ on the output performances of 2 DOFs right-angle-shape piezoelectric energy harvester: (a) the first two order natural frequency; (b) the operation bandwidth of two beams.

\section{The out-power of the optimized 2-DOFs right-angle-shape piezoelectric energy harvester}

According to above researches, size parameters of 2-DOFs right-angle-shape piezoelectric energy harvester which shown in Table II are selected as the optimized device size. The electrical energy on the two piezoelectric patches of optimized 2-DOFs right-angle-shape piezoelectric energy harvester is recovered by the Standard interface circuit ${ }^{[12]}$. The maximum output power of the optimized device are studied by simulation in this section.

TABLE II. Size Parameters of the Device

\begin{tabular}{|c|c|c|c|c|c|c|}
\hline & $\begin{array}{c}\text { Main } \\
\text { beam }\end{array}$ & $\begin{array}{c}\text { Main } \\
\text { piezoele- } \\
\text { ctric } \\
\text { patch }\end{array}$ & $\begin{array}{c}\text { Secondary } \\
\text { beam }\end{array}$ & $\begin{array}{c}\text { Secondary } \\
\text { piezoele } \\
\text {-ctric } \\
\text { patch }\end{array}$ & Mass1 & Mass2 \\
\hline $\begin{array}{c}\text { Length } \\
\text { (mm) }\end{array}$ & 50 & 40 & 60 & 50 & 10 & 10 \\
\hline $\begin{array}{c}\text { Width } \\
\text { (mm) }\end{array}$ & 10 & 10 & 10 & 10 & 10 & 10 \\
\hline $\begin{array}{c}\text { Thick } \\
\text {-ness } \\
\text { (mm) }\end{array}$ & 0.5 & 0.3 & 0.5 & 0.3 & 10 & 10 \\
\hline
\end{tabular}

The output power of optimized 2-DOFs right-angle-shape piezoelectric energy harvester at the first two order resonant frequency are shown in Fig.4. At the first resonant frequency, when load resistor $R_{L}=200 \mathrm{k} \Omega$, the output power of two beams reach the maximum $4.8 \mathrm{~mW}$ and $41 \mathrm{~mW}$ respectively. At the second resonant frequency, when load resistance $R_{L}=100 \mathrm{k} \Omega$, the output power of two beams reach the maximum $25 \mathrm{~mW}$ and $10.5 \mathrm{~mW}$ respectively.
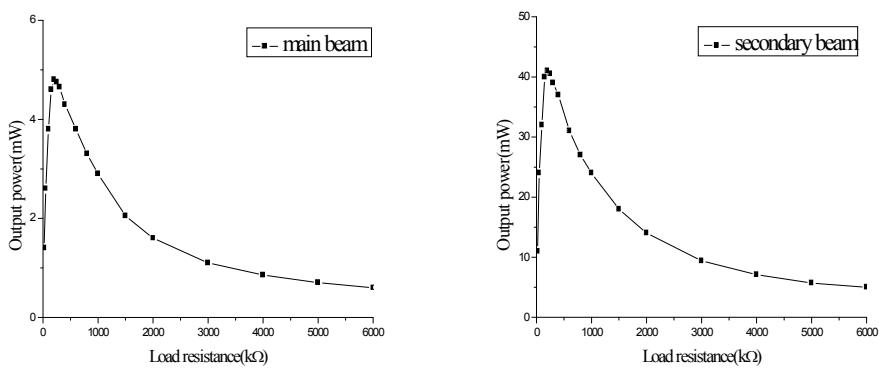

(a) 

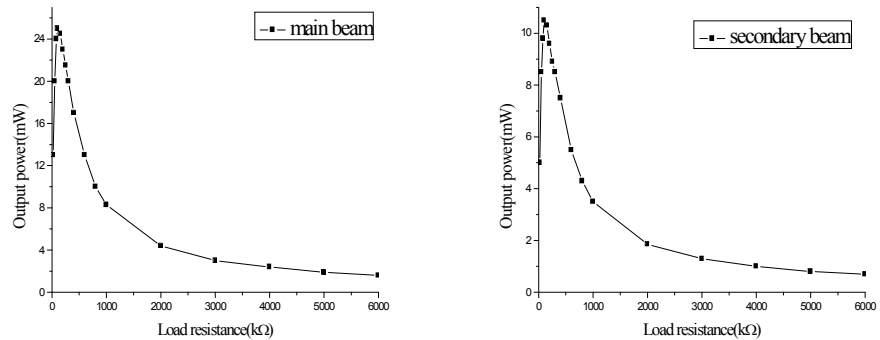

(b)

Fig.4. The output power of optimized device at the first two order resonant frequency: (a) the first resonant frequency; (b) the second resonant frequency.

The property parameters of the optimized 2-DOFs rightangle-shape piezoelectric energy harvester and the compare with other piezoelectric energy harvesters are listed in Table III. The design of the piezoelectric energy harvester presented in reference5 and reference6 although broadening the operation bandwidth, the output power density is very low, and natural frequency is still high. The design of the multiDOFs piezoelectric energy harvester presented in reference7 and reference8 can effectively reduce the natural frequency, generate multiple operating frequency bands at low-frequency environment, but the sum of operation bandwidth is still narrow, and the output power density is relatively low. Compared with the devices above, the harvester attached with multiply mass presented in reference9 reduces the natural frequency, increase the output power density, but the widening of operation bandwidth is not desired. The property parameters of 2-DOFs right-angle-shape piezoelectric energy harvester in this paper are better than reference9 in natural frequency, effective band width, and power density. Therefore 2-DOFs right-angle-shape piezoelectric energy harvester could be efficient and adaptive in low-frequency vibration environment

TABLE III. The Property Parameters of Optimized Device and Other Piezoelectric Energy Harvesters

\begin{tabular}{|c|c|c|c|c|c|c|}
\hline Reference & Acceleration $(\mathrm{g})$ & $\begin{array}{l}\text { First resonant } \\
\text { frequency }(\mathrm{Hz})\end{array}$ & $\begin{array}{c}\text { operating frequency } \\
\text { bands }(<100 \mathrm{~Hz})\end{array}$ & $\begin{array}{c}\text { Operation } \\
\text { bandwidth(Hz) }\end{array}$ & $\begin{array}{c}\text { Output } \\
\text { power }(\mu W)\end{array}$ & $\begin{array}{l}\text { Power density } \\
\left(\mu \mathrm{W} / \mathrm{mm}^{3}\right)\end{array}$ \\
\hline 5 & 1.0 & 93 & 1 & 18 & 58 & 0.018 \\
\hline 6 & 4.6 & 118 & 0 & 20 & 340 & 0.458 \\
\hline 7 & 0.1 & 17.4 & 2 & 3 & 800 & 0.1 \\
\hline 8 & 1.0 & 14.3 & 3 & 2.7 & 337.5 & 0.034 \\
\hline 9 & 1.0 & 39 & 1 & 10 & 96000 & 12.5 \\
\hline This work & 1.0 & 21.67 & 2 & 14.2 & 41000 & 13.22 \\
\hline
\end{tabular}

\section{CONCLUSION}

In this paper, a 2-DOFs right-angle-shape piezoelectric energy harvester is designed, and theoretical analysis of device vibration and the effect of size parameters on the output performances of device are discussed. Based on above researches, the optimal size is selected as shown in Table II. Simulation results show that natural frequency of the device are $f_{1}=21.7 \mathrm{~Hz}, f_{2}=48.75 \mathrm{~Hz}$ respectively, the output voltage of main and secondary beam at the first resonant frequency are $12.2 \mathrm{~V}$ and $6.8 \mathrm{~V}$ respectively, and the output voltage of main and secondary beam at the second resonant frequency are $18.5 \mathrm{~V}$ and $7.4 \mathrm{~V}$. The operation bandwidth of two beams are $13.8 \mathrm{~Hz}$ and $14.2 \mathrm{~Hz}$ respectively, and maximum output power reaches $25 \mathrm{~mW}$ and $41 \mathrm{~mW}$ respectively. It is demonstrated that 2-DOFs right-angleshape piezoelectric energy harvester not only reduces each order natural frequency, increases the output-power density, but also ensures the wide operation bandwidth. It could be suitable for low-frequency vibration environment and matching for energy harvesting. And the influence of the cross section parameters on the output performances of piezoelectric energy harvester would be studied and optimized in further.

\section{References}

[1] A. S. Almazyad, Y. M. Seddiq, A. M. Alotaibi, et al. "A proposed scalable design and simulation of wireless sensor network-based long-distance water pipeline leakage monitoring system,"J. Sensors, vol.14, pp. 3557-3577, February 2014.

[2] M. G. Ippolito, M. L. D. Silvestre, E. R. Sanseverino, "Multiobjective optimized management of electrical energy storage systems in an islanded network with renewable energy sources under different design scenarios," J. Energy, vol. 64, pp. 648-662, January 2014.

[3] Y. Uzun, E. Kurt. "The effect of periodic magnetic force on a piezoelectric energy harvester," J. Sensors and Actuators A Physical, vol.192, pp. 58-68, 2013.

[4] D. P. Arnold. "Review of microscale magnetic power generation," J. IEEE Transactions on Magnetics, vol. 43, pp. 3940-3951, November 2007.

[5] K. A. Singh, R. Kumar, R. J. Weber. "A broadband bistable piezoelectric energy harvester with nonlinear high-power extraction," J. IEEE Transactions on Power Electronics, vol. 30, pp. 6763-6774, December 2015.

[6] H. Wu, L. Tang, Y. Yang, et al. "A novel two-degrees-of-freedom piezoelectric energy harvester," J. Journal of Intelligent Material Systems and Structures, vol. 24, pp. 357-368, February 2013.

[7] Y. Hu, Y. Xu. "Multi-resonant wideband energy harvester based on a folded asymmetric M-shaped cantilever,” J. Aip Advances, vol. 5, pp. 902-904, July 2015.

[8] H. Wang, X. Zhou, W. Qiu, et al. "Simulation and experiments of broadband piezoelectric energy harvesting devices," C. IEEE International Conference on micro Engineered and Molecular Systems. IEEE, 2014

[9] J. W. Yi, W. Y. Shih, W. H. Shih. "Effect of length, width, and mode on the mass detection sensitivity of piezoelectric unimorph cantilevers," J. Journal of Applied Physics, vol. 91, pp. 1680-1686, February 2002.

[10] G.Tang. "Research on MEMS energy harvester based on piezoelectric thick film,” D. Shanghai Jiao Tong University, 2013.

[11] A. Y. Tang. "Vibration analysis of beams with variable stiffness," D. Central South University, 2014.

[12] P. H. Hsieh, C. H. Chen, H. C. Chen. "Improving the Scavenged Power of Nonlinear Piezoelectric Energy Harvesting Interface at OffResonance by Introducing Switching Delay,” J. Power Electronics IEEE Transactions on, vol. pp. 3142-3155, June 2015 